\title{
Critical Role of Protein Kinase C (PKC) in the Onset of Airway Hypersensitivity in Ova-Sensitized Guinea Pig Model of Asthma
}

\author{
Rakesh Kumar Mishra ${ }^{1}$, Ritu Kulshrestha ${ }^{2}$, Sunil Kumar Chhabra ${ }^{3}$, Satish K. Srivastav ${ }^{4}$, \\ Surendra Kumar Bansal ${ }^{*}$ \\ ${ }^{1}$ Department of Biochemistry, V.P. Chest Institute, University of Delhi, Delhi, India \\ ${ }^{2}$ Department of Pathology, V.P. Chest Institute, University of Delhi, Delhi, India \\ ${ }^{3}$ Department of Cardiorespiratory Physiology, V.P. Chest Institute, University of Delhi, Delhi, India \\ ${ }^{4}$ Department of Biochemistry and Molecular Biology, The University of Texas Medical Branch, Galveston, USA \\ Email: "bansalsurendrak@yahoo.com
}

Received November 29, 2013; revised December 30, 2013; accepted January 6, 2014

Copyright (C) 2014 Rakesh Kumar Mishra et al. This is an open access article distributed under the Creative Commons Attribution License, which permits unrestricted use, distribution, and reproduction in any medium, provided the original work is properly cited. In accordance of the Creative Commons Attribution License all Copyrights $(2014$ are reserved for SCIRP and the owner of the intellectual property Rakesh Kumar Mishra et al. All Copyright (C) 2014 are guarded by law and by SCIRP as a guardian.

\section{ABSTRACT}

Background and Objectives: Protein kinase C (PKC) activation plays an important role in activation of T-lymphocytes in asthma. Airway hypersensitivity is one of the main characteristic features of asthma, the mechanism of onset of which is not clearly understood. Therefore, the objective was to elucidate the role of PKC in etiopathogenesis of airway hypersensitivity in asthma. Methods: Male guinea pigs $(n=30)$ were sensitized with ovalbumin and day of initial allergen-specific immune response determined by intradermal test, airway hypersensitivity, BALF cytology and lung histopathology. Total PKC activity, PKC isoenzymes and phosphoinositides were assessed in airway smooth muscles (ASM) and peripheral blood lymphocytes. Results: Intradermal test revealed that day 9 was the earliest time of allergen-specific response and onset of airway hypersensitivity to ovalbumin. It was associated with significant increase in total and differential (lymphocytes and eosinophils) BALF counts and grade I peribronchiolar chronic lymphocytic inflammation in lung. On day 14, grade II infiltration of lymphocytes and eosinophils with onset ofstructural remodelingofproximal and distal airways was seen. Total PKC activity, expression of PKC $\alpha, P K C \varepsilon$ and phosphoinositides increased significantly in ASM and lymphocytes on day 9 and were maximum on day 14. There was no change in PKC- $\tau$ expression. Conclusions: Activation of PKC, particularly $\mathrm{PKC} \alpha$ and $\mathrm{PKC} \varepsilon$, mediated signal transduction pathway plays a critical role in lymphocyte infiltration and onset of airway hypersensitivity, airway remodeling and asthma pathophysiology. The present study is the first one on the mechanism of the etiopathogenesis of the disease, which shows a direct evidence of the role of PKC mediated pathway in the initiation and onset of airway hypersensitivity in ovalbumin sensitized guinea pig model.

\section{KEYWORDS}

Asthma; Airway Hypersensitivity; Protein Kinase C; Airway Remodelling

\section{Introduction}

Asthma affects approximately $10 \%$ of the population in the United States and its prevalence has almost doubled in the past 20 years [1,2]. In India, its prevalence varies between $2.4 \%$ to $31.14 \%$ from different parts of the country $[3,4]$. Airway inflammation, persistent airway

\footnotetext{
"Corresponding author.
}

hyper-responsiveness (AHR) and airway obstruction are the main characteristics of asthma [5]. Onset of thisdisease starts with the sensitization to an allergen, followed by IgE-mediated response, mast celldegranulation, bronchoconstriction and recruitment of inflammatorycells. In addition, during progression of the disease, structural changes in the airways like; goblet cell hyperplasia, smooth muscle thickening and subepithelial and airway 
wall fibrosis are known to occur [6-10].

Asthma is triggered by various stimuli including virus, environmental pollutants, tree and weed pollens, cold air, exercise etc. [11,12]. The response of airway cells to these stimuli is mediated through activation of distinct transmembrane signaling intermediates [13]. The activation of protein kinase $\mathrm{C}$ (PKC) signaling pathway is one of the key players in asthma pathogenesis $[14,15]$. Previously, we and others have shown that inhibition of PKC reduces the activation of lymphocytes, inhibits the expression of Th2 cytokines by $\mathrm{T}$ lymphocytes from asthmatic patients [16,17], abolishes airway smooth muscles constriction [18], and inhibits the proliferation and structural changes in airway smooth muscle cells from asthmatic rats [19]. In another study, inhibition of PKC by calphostin-C, prevented proliferation of bovine tracheal smooth muscle cells following activation of mannose receptors by $\beta$-hexosaminidase and also abolished $\mathrm{Ca}^{2+}$-dependent and -independent PKC activity [20] which suggests involvement of different isoenzymes of PKC.

Thus, it is evident that PKC plays a pivotal role in the pathophysiology of asthma. In most of the studies, investigations were carried out after the disease was established and there is no report available on the role of PKC in the etiopathogenesis of the disease. We, therefore, hypothesized that PKC mediated signal transduction pathway might be playing an important role in the onset of the diseases. Since airway inflammation, hypersensitivity and tissue remodeling are the characteristic features of asthma, therefore, first of all we investigated the day of onset of these features followed by the process of PKC activation and expression of its isoenzymes at the onset of the disease using guinea pig model of asthma developed by ovalbumin induced IgE response. The studies were conducted on the airway smooth muscles being the targetsd in lung and the lymphocytes as the inflammatory cweslls (obtained from peripheral blood) and brocn-choalveolar lavage fluid (BALF) for cytological changes and lungs for histopathological changes to assess the pulmonary inflammation. Our results demonstrate that the first ova-specific immune response i.e. onset of the hypersensitivity, can be observed on day 9 after ova-sensitization in the guinea pigs, which coincided with the onset of airway hypersensitivity, increased total PKC activity, and increased expression of PKC $\alpha$ and PKC $\varepsilon$ isoenzymes. These changes were associated with mild peribronchiolar lymphocytic infiltration and progressive eosinophilic infiltration, suggesting role of PKC in the pathogenesis of the onset of airway inflammation and the disease.

\section{Materials and Methods}

\subsection{Ethics Statement}

The study was approved by the Animal Ethics Commit- tee of Vallabhbhai Patel Chest Institute, University of Delhi, Delhi, India.

\subsection{Study Design}

The experiments were conducted on guinea pigs. The animals were sensitized by ovalbumin using standards protocol. The control group received the vehicle alone. The sensitization of the animals was checked every day by intradermal (ID) test using ovalbumin. The day, the sensitized animals showed a positive reaction for the first time, was recorded. The airway responsiveness to ovalbumin was measured by non-invasive body-plethysmography technique daily starting from on day 0 (baseline) till the day when the sensitization was observed by intradermal test for the first time (onset) and finally the day of maximum positivity. Besides it, the cytology BALF and histopathology of lung tissue was also performed to assess the airway changes in the lungs. These parameters established day 9 to be the day of onset of hypersensitivity and day 14 to be the day of maximum hyper-responsiveness. The animals were divided in two main groups, the control an experimental. Each group had 15 animals. Five animals from each group were taken for experiments on day 0, day 9 and day 14 .

Blood was collected from each animal directly from the heart for preparing the peripheral blood lymphocytes. The animals were then sacrificed by cervical dislocation. For assessment of inflammatory changes, bronchoalveolar lavage fluid (BALF) was collected for cytology and lung removed and preserved for histopathological examination. For biochemical studies, the trachea and bronchi were removed and airway smooth muscles (ASM) dissected out. The ASM homogenate and lymphocyte lysate were prepared, followed by identification, characterization and quantification of phosphoinositides by thin layer chromatography (TLC), total PKC activity assay by radio-binding and histone phosphorylation methods, PKC isoenzymes by Western blot and identification of target proteins of PKC by protein phosphorylation. The data were analyzed statistically. $\mathrm{P}<0.05$ was considered significant. The study was approved by the Animal Ethics Committee of the Institute.

\subsection{Chemicals and Reagents}

Radioactive Chemicals: $\left[{ }^{3} \mathrm{H}\right]$ Phorbol 12, 13 dibutyrate $\left(\left[{ }^{3} \mathrm{H}\right] \mathrm{PDBu}\right.$ ) (specific activity $23.5 \mathrm{Ci} / \mathrm{mM}$ ), was purchased from Amersham Biosciences UK. $\left[{ }^{32} \mathrm{P}\right]-\gamma$-ATP (specific activity $4000 \mathrm{Ci} / \mathrm{mM}$ ) was purchased from BRIT, Mumbai, India.

Immunochemicals: Anti-peptide monoclonal antibodies to $\mathrm{PKC} \alpha, \varepsilon$, $\tau$, were procured from Transduction Laboratories (Lexington, Kentucky). Horseradish peroxidase-conjugated rabbit anti-mouse IgG was purchased 
from Sigma Laboratories (St. Louis, Missouri, USA).

Biochemicals, chemicals and other supplies: Acrylamide, adenosine triphosphate (ATP), bis-acrylamide, dithiothreitol (DTT), ethylene diamine tetra acetic acid (EDTA), ethylene glycol bis ( $\beta$-amino ethylene) tetra acetic acid (EGTA), histopaque (sp. gravity 1.077), ovalbumin (Grade V), phenyl methyl sulphonyl fluoride (PMSF), L- $\alpha$ phosphatidyl inositol (PI), L- $\alpha$ phosphatidyl inositol 4 monophospahte (PIP), L- $\alpha$ phosphatidyl inositol 4, 5 bisphospahte (PIP2), L- $\alpha$ phosphatidyl serine (PS) sodium lauryl sulphate (SDS), trizma base, tetramethylethylenediamine (TEMED) were purchased from Sigma Chemical Co. St Louis, USA. Molecular weight markers (prestained low range), and PVDF membrane were purchased from Bio-Rad Pacific, Ltd. (Kowloon, Hong Kong). Ammonium per sulphate (APS), bovine serum albumin (BSA), diaminobenzidine (DAB) and Tween-20, were purchased from SiscoResearch Laboratories (Mumbai, India). Aluminium hydroxide gel (dried) was purchased from Central Drug House (CDH), Bombay, India. Heparin was purchased from Biological Evans Ltd. (Hyderabad, India). All other chemicals used were of analytical grade.

\subsection{Animals}

Male Dunkin-Hartley guinea pigs (30 nos.) weighing 350 - $450 \mathrm{~g}$ were obtained from the V.P. Chest Institutemaintained animal colony. The animals were kept under the condition of husbandry on standard pellet diet and water ad libitum and maintained as per the guidelines for care and use of animals in scientific research issued by Indian National Science Academy, India. The project was approved by the Animal Ethics Committee of the Institute. The animals were divided in two main groups, Group I: control and group II: experimental. Each group had 15 animals. Five animals from each group were taken for experiments on day 0 , day 9 and day 14 .

\subsection{Sensitization of Guinea Pigs}

The animals were sensitized with $100 \mu \mathrm{g}$ ovalbumin and $100 \mathrm{mg}$ aluminum hydroxide per $\mathrm{ml}$ of normal saline [21]. Control group animals received the vehicle alone. The antigen-adjuvant solution was agitated vigorously on a vortex mixer for 90 minutes and $0.5 \mathrm{ml}$ injected intraperitoneally and $0.5 \mathrm{ml}$ subcutaneously by dividing the amount equally among 5 different sites near the lymph nodes, viz. cervical, axillary, lumbar regions, neck and inguinal. This protocol results in sensitization of guinea pigs.

\subsection{Intradermal Test (i.d.)}

For intradermal test, left pinna of the ear was cleaned with alcohol and dorsal surface was injected with $25 \mu \mathrm{l}$ of normal saline or same volume of $0.2 \mathrm{mg} / \mathrm{ml}$ ovalbumin. Histamine solution $(5 \mathrm{mg} / \mathrm{ml})$ and physiological saline were used as positive and negative controls, respectively. After 12 to 15 minutes the skin was checked for red, raised, itchy areas (wheal), formation of which indicates an allergen-specific positive immune reaction. Sensitization was considered complete by the doubling of wheal size. The thickness of the ear lobes of the animals was measured.

\subsection{Specific Airway Conductance (SGaw)}

SGaw was determined by dividing airway conductance by the lung volume (SGaw $=\mathrm{Gaw} / \mathrm{TGV})$. It was measured by non-invasive whole body plethysmography technique [20]. Briefly, the box pressure and airflow was measured (Validyne PM 18 differential transducers) and the signal amplified (CD 12 carrier demodulators). The box pressure signal was fed on the $\mathrm{X}$ channel and airflows on the $\mathrm{Y}$ channel of oscilloscope (Hewlett-Packard, USA) to obtain an X-Y plot [22].

\subsection{Collection of Broncho-Alveolar Lavage Fluid and Cytology}

The bronchoalveolar lavage fluid (BALF) was collected by exposing the trachea as per the method described earlier [23], and physiological saline $\left(8 \mathrm{ml}, 37^{\circ} \mathrm{C}\right)$ was injected in the lung and lavaged twice. The lavage fluid obtained was centrifuged at $500 \times \mathrm{g}$ for $10 \mathrm{~min}$ at $4^{\circ} \mathrm{C}$. The cell pellet was given osmotic shock to eliminate the erythrocyte contamination as described by Bansal [24]. The cell suspension was centrifuged as before, pellet washed twice with saline and resuspended in $100 \mu \mathrm{l}$ saline. The total cell count was performed using a Neubaur's Counting Chamber. Smears were stained with Giemsa stain and differential count performed on at least 300 cells in each case.

\subsection{Histopathology of Lung}

A histopathological study of lungs was carried out as described by Underwood et al. [25]. Briefly, the lungs were removed, half the portion fixed by slowly inflating with buffered formaline and subsequently embedding in paraffin. $5 \mu \mathrm{m}$ thick sections were stained with haematoxylin and eosin. Lung parenchyma was assessed for changes in bronchi and bronchioles. Peribronchiolarinflammation was assessed and graded on the scale of 0 - 3 [26]. Gomori's stain for reticular fibers to demonstrate thickening of the sub-epithelial lamina reticularis and Masson Trichrome stain to demonstrate sub-epithelial collagenization were also used. 


\subsection{Preparation of Airway Smooth Muscles (ASM) Extract}

The trachea was harvested after sacrificing the animal, and adhering extraneous material to it was carefully removed, smooth muscle portion dissected out, washed in chilled saline and soaked over a clean filter paper. The tissue was then weighed and suspended in 9 volumes of homogenizing buffer $(25 \mathrm{mM}$ tris $\mathrm{HCl} p \mathrm{H} 7.5,2 \mathrm{mM}$ EGTA, 2 mM EDTA, 2 mM DTT, 1 mM PMSF, 250 $\mathrm{mM}$ sucrose) and homogenized in a glass homogenizer in an ice-water bath. Homogenate was then centrifuged at $700 \times \mathrm{g}$ for $5 \mathrm{~min}$ as above and supernatant used for subsequent analysis.

\subsection{Preparation of Peripheral Blood Lymphocytes (PBL) Lysate}

The peripheral blood lymphocytes were isolated by the method of Boyum [27]. Briefly, blood was diluted 1:1 with saline and carefully layered over histopaque (specific gravity 1.077) and centrifuged at $2000 \mathrm{rpm}$ (Rotor no. 9, Rota 4R-V/FM Plasto Crafts, Mumbai, India) for 10 minutes. The opaque ring at the interface containing lymphocytes was collected, diluted with saline and centrifuged at $1500 \mathrm{rpm}$ for 10 minutes. The pellet was washed twice with saline. Contaminating erythrocytes were lysed by incubating the pellet in $0.85 \%$ ammonium chloride solution. The PBL lysate was prepared by sonicating the cell suspension in the homogenizing buffer in an Ultrasonicator (Misonix Ultrasonic Processor XL2020) by giving five bursts of 30 sec each at an interval of one min at $0^{\circ} \mathrm{C}$ in an ice-water bath. The cell lysate was centrifuged at $700 \times \mathrm{g}$ for 5 minutes and supernatant saved for subsequent analysis.

\subsection{Protein Estimation}

Protein contents of the ASM extracts and PBL lysate were quantified by the method of Lowry et al. [28]. Equal amount of proteins from different experimenttal groups was used for further analyses and determinations.

\subsection{Phosphoinositide Assay}

Phosphoinositides were extracted and resolved by TLC as described by Bansal et al. [29]. Briefly, the ASM homogenate or lymphocytes lysate $(0.5 \mathrm{ml})$ in $10 \mathrm{mM} \mathrm{LiCl}$ solution containing one mg total protein was thoroughly mixed with $1.8 \mathrm{ml}$ of acidified chloroformmethanol mixture $\left(\mathrm{CHCl}_{3}: \mathrm{CH}_{3} \mathrm{OH}: \mathrm{HCl} ; 100: 200: 2 ; \mathrm{v} / \mathrm{v} / \mathrm{v}\right)$, followed by addition of $0.6 \mathrm{ml}$ of chloroform and $0.6 \mathrm{ml}$ of $2 \mathrm{M} \mathrm{KCl}$. After thorough mixing, the contents were centrifuged at $500 \mathrm{~g}$ for $5 \mathrm{~min}$ at room temperature, aqueous and organic phases carefully separated and saved in separate tubes. The pellet was washed again with 2 volumes of acidified chloroformmethanol mixture and aqueous and organic phases carefully separated and pooled. Organic phase containing phospholipids was dried under the stream of $\mathrm{N}_{2}$ and stored at $4^{\circ} \mathrm{C}$ till analyzed. Phospholipids were resolved by TLC on silica gel G plates impregnated with $1 \%$ potassium oxalate and $1 \mathrm{mM}$ EDTA [30]. The spots corresponding to the standards were scraped. The bands of each phosphoinositide were processed for estimation of total phosphorus by the direct gel digestion method of Misra [31].

\subsection{Protein Kinase C (PKC) Assay}

PKC in ASM extracts and PBL lysate was assayed by two different methods viz. radio-ligand binding assay and histone IIIS phosphorylation as described earlier [32].

For radio-ligand binding assay, briefly, to $25 \mu \mathrm{l}$ of reaction mixture (50 mM tris $\mathrm{HCl}, \mathrm{pH} 7.5,1 \mathrm{mM} \mathrm{CaCl}_{2}$, $0.1 \%$ BSA, $20 \mathrm{mM} \mathrm{MgCl}_{2} \cdot 6 \mathrm{H}_{2} \mathrm{O}, 2 \mathrm{mM}$ DTT, $5 \mathrm{mg} / \mathrm{ml}$ phosphatidyl serine (PS) and $1 \mu \mathrm{Ci} / \mathrm{ml}\left[{ }^{3} \mathrm{H}\right]-\mathrm{PDBu}$ ) in triplicate, $25 \mu$ sample (30 - $50 \mu \mathrm{g}$ protein) was added to each tube to start the reaction and contents incubated at $30^{\circ} \mathrm{C}$ for 25 minutes. In one of the test tubes, phorbol 12-myristate 13-acetate (PMA) was added (final conc 5 $\mu \mathrm{M})$ which served as control for the non-specific binding. The reaction was terminated by adding $2 \mathrm{ml}$ chilled 10 $\mathrm{mM}$ tris-hydrochloride ( $p \mathrm{H} 7.5)$. The contents were filtered on what man glass fibre filter (25 mm GF/C), washed twice with chilled $10 \mathrm{mM}$ tris $\mathrm{HCI}(p \mathrm{H} \mathrm{7.5)}$ and processed for radioactivity counting in a liquid scintillation counter (Beckman LS 6500). PKC activity was expressed as femtomoles $\left[{ }^{3} \mathrm{H}\right]$-PDBu bound per mg protein under the experimental conditions.

For histone IIIS phosphorylation assay, the standard reaction mixture $(50 \mu \mathrm{l})$ containing $50 \mathrm{mM}$ tris $\mathrm{HCl} p \mathrm{H}$ 7.5, $50 \mu \mathrm{M}$ ATP, $10 \mu \mathrm{mM} \mathrm{MgCl} \cdot 6 \mathrm{H}_{2} \mathrm{O}, 100 \mu \mathrm{M}$ $\mathrm{CaCl}_{2} \cdot 2 \mathrm{H}_{2} \mathrm{O}, 50 \mu \mathrm{g}$ histone IIIs, $5 \mu \mathrm{g}$ PS and ${ }^{32} \mathrm{P}-\gamma$-ATP $(0.1 \mu \mathrm{Ci}$, sp. activity $4000 \mathrm{Ci} / \mathrm{mM})$ was kept on ice. The reaction was started by addition of $50 \mu \mathrm{l}$ of sample containing $50 \mu$ g proteins. The tubes were vortexed and incubated for 3 minutes at $30^{\circ} \mathrm{C}$ in a metabolic shaker. The reaction was stopped by the addition of one $\mathrm{ml}$ chilled $20 \%$ trichloroacetic acid (TCA). Acid precipitable material was collected on a Millipore membrane filter HA type $(25 \mathrm{~mm}, 0.45 \mu \mathrm{m})$ under vacuum using a manifold filtration device (Millipore). The filters were washed with one $\mathrm{ml}$ of TCA (10\%) followed by washing with 2 $\mathrm{ml}$ ethanol, transferring of the filters into scintillation vials containing $5 \mathrm{ml}$ dioxane-based scintillation fluid and counting of radioactivity using Beckman LS 6500 liquid scintillation counter. PKC activity was expressed as femtomoles of ${ }^{32} \mathrm{P}$-transferred to histone IIIs per mg protein under experimental conditions. 


\subsection{Identification of PKC Isoenzymes by Western Blot Analysis}

Equal amounts ofthe ASM extract and PBL lysate proteins $(50 \mu \mathrm{g})$ were separately mixed with sample buffer, boiled for 5 minutes, resolved by SDS-PAGE on $10 \%$ polyacrylamide gel electrophoresis and transferred to PVDF membrane. Positive control for each isoenzyme was run simultaneously. The membrane was incubated with blocking buffer ( $2 \%$ BSA in $10 \mathrm{mM}$ Tris $\mathrm{HCl} ; p \mathrm{H}$ $7.5,100 \mathrm{mM} \mathrm{NaCl}, 0.1 \%$ tween-20) at $37^{\circ} \mathrm{C}$ for $45 \mathrm{mi}-$ nutes and washed thrice with wash buffer $(10 \mathrm{mM}$ Tris $\mathrm{HCl} ; p \mathrm{H} \mathrm{7.5,} 100 \mathrm{mM} \mathrm{NaCl}$ and $0.1 \%$ tween-20) for 10 minutes each. The membrane was incubated with primary antibodies (monoclonal, diluted as per the instructions of the manufacturer, M/S Transduction Laboratories, Lexington, Kentucky, USA) for overnight at $4^{\circ} \mathrm{C}$ and then washed thrice in wash buffer as before and incubated with second antibody (HRP-conjugate) for $30 \mathrm{~min}$ at $37^{\circ} \mathrm{C}$. Bands were visualized using a horseradish peroxidase-conjugated anti-rabbit IgG Ab (Cell Signaling Technology) and chemiluminescence (Amersham Biosciences, Piscataway, NJ, USA). Signals on X-ray film were scanned using a Bio-Rad GS 800 densitometer. For stripping, membranes were incubated with stripping buffer (Thermo Scientific, Rockford, IL, USA) at $37^{\circ} \mathrm{C}$ for $30 \mathrm{~min}$, then washed, blocked and reprobed overnight at $4^{\circ} \mathrm{C}$ with monoclonal mouse anti- $\beta$-actin antibody (1:10.000; Sigma).

\subsection{Statistical Analysis}

Statistical analysis was done by using "Prism" software. Students " $\mathrm{t}$ " test was applied to compare the groups. P < 0.05 was considered significant.

\section{Results}

\subsection{Determination of Onset of Immune Response, Airway Hypersensitivity and Inflammatory Changes in OVA-Sensitized Guinea Pigs}

\subsubsection{Determination of Day of Onset of Immune Response}

Intradermal test (i.d.) is the most common screening method for allergy evaluation. A positive i.d. is an indirect measurement of allergen-specific IgE level. First of all, we determined the ovalbumin-specific immune response in the sensitized animals by i.d. On day 0, there was no reaction by treatment of normal saline or ovalbumin, while histamine, used as positive control, showed a $6 \mathrm{~mm}$ diameter wheal. On day 9, in sensitized group, the ovalbumin-specific wheal size in experimental group was 3.2 $\pm 0.28 \mathrm{~mm}(\mathrm{P}<0.0001$ as compared to the control group).
This was the first day when animals in experimental group showed positive response to i.d. post-sensitization, which indicated the onset of immune reaction to ovalbumin. Further, on day 14, the sensitized animals showed maximum intradermal test positivity $(6.22 \pm 0.02 \mathrm{~mm}$ diameter, $\mathrm{P}<0.0001$ as compared to the control group) against ovalbumin, indicating complete sensitization.

\subsubsection{Determination of Airway Hyper-Responsiveness during Onset of Immune Response}

After determining the allergen specific immune response, we measured the specific airway conductance (SGaw) on days 1 - 14 in control and sensitized guinea pigs. On day 0 , the SGaw of control group was $0.95 \pm 0.02 \mathrm{sec}^{-1} \mathrm{~cm}$ $\mathrm{H}_{2} \mathrm{O}^{-1}$ (Mean \pm SEM) and that of experimental group (immediately after sensitization) was $0.89 \pm 0.03$. There was no significant change in SGaw between day 1 and 8 (data not shown) in sensitized group as compared to the control group. However, on day 9, there was $>35 \%$ $(36.88 \% \pm 0.55 \%)$ fall in SGaw after ovalbumin inhalation in experimental group while in control group the fall was only $21.80 \pm 1.250$ and the changes were statistically significant $(\mathrm{P}<0.0001)$, indicating that day 9 was the accurate time point of onset of the airway hypersensitivity after sensitization. On day 14, there was a further decrease $(43.91 \% \pm 2.131 \%)$ in SGAw $(\mathrm{P}<0.0001)$ as compared to control $(21.14 \pm 1.60)$. Since there was no significant change in SGawon day 7 and 8, we concluded day 9 to be the day of onset of airway hypersensitivity.

\subsection{Determination of Cytological, Pathological and Biochemical Changes during the Onset of Airway Hypersensitivity}

\subsubsection{Changes in BALF}

BALF total and differential cell count was done on day 0, 9 and 14 in control and experimental group animals. The total BALF cell count in control group on day 0 was 1.9 $\pm 0.14 \times 10^{6}$ cells/animal. In experimental group on day 0 there was no significant change, but on day 9 , a significant increase in the total cell count to $3.925 \pm 0.09 \times 10^{6}$ cells/animal $(\mathrm{P}<0.001)$ and on day 14 to $6.203 \pm 0.12 \times$ $10^{6}$ cells/animal $(\mathrm{P}<0.001)$ was observed. BALF differential cell count revealed that, in control group on day 0 Figure 1(a)-(c), alveolar macrophages were $76.5 \% \pm$ $1.70 \%$ (Mean \pm SEM), lymphocytes were $21.70 \% \pm$ $1.67 \%$, neutrophils were $1.10 \% \pm 0.32 \%$, and eosinophils were $0.7 \% \pm 0.00 \%$.

On day 9, BALF macrophages significantly decreased to $59.75 \% \pm 2.22 \%$ (Mean $\pm \mathrm{SEM})(\mathrm{P}<0.0001)$ associated with increase in eosinophils to $4.33 \% \pm 1.611 \%$ (P $=0.002$ ), and transient neutrophilia to $18.00 \% \pm 3.90 \%$, while lymphocytes remained almost similar when compared to control. 


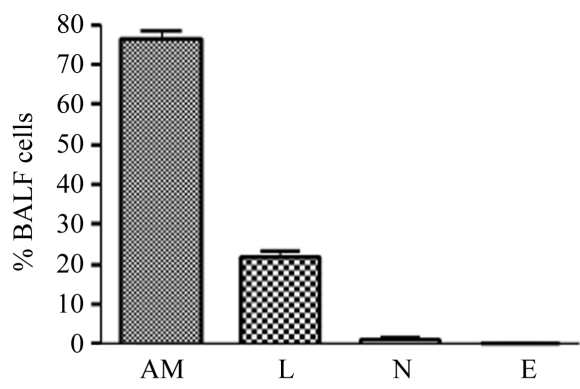

(a)

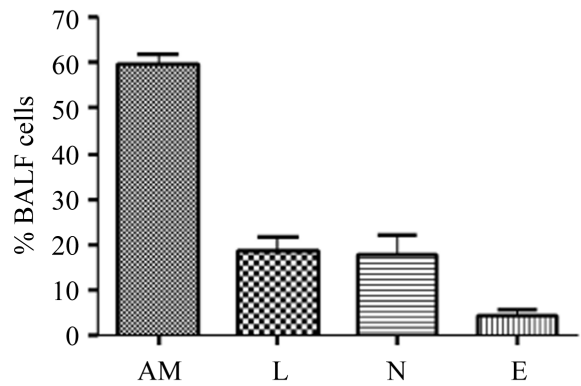

(b)

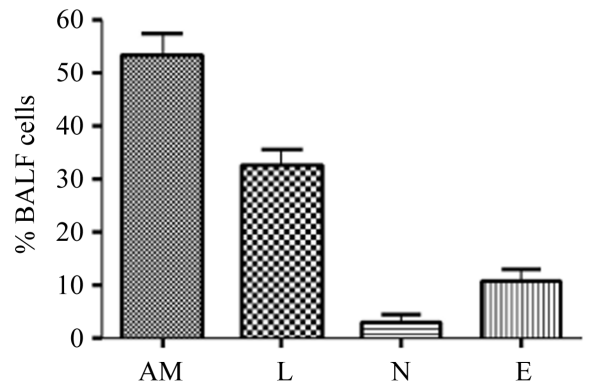

(c)

Figure 1. BALF differential cell count (a) Control group i.e. on day 0 , comprising predominantly of $\mathrm{AM}$, (b) On day 9, Significant increase in $\mathrm{N}$ and $\mathrm{E}(\mathrm{P}=\mathbf{0 . 0 0 2}$ and $\mathrm{P}=\mathbf{0 . 0 1 6}$ respectively) as compared to control and (c) on day 14, AM showed significant decrease to $53.20 \% \pm 4.23 \%(\mathrm{P}<0.0001)$ and a significant increase in $\mathrm{E}$ to $10.80 \% \pm 2.48 \%,(P=0.0001)$ as compared to control. AM = Alveolar Macrophages, $\mathbf{N}=$ Neutrophils, $\mathrm{E}=$ Eosinophils and $\mathrm{L}=$ Lymphocytes.

On day 14, the alveolar macrophages showed further decrease to $53.20 \% \pm 4.23 \%$ ( $\mathrm{P}<0.0001)$ as compared to control. There was a significant increase in eosinophils to $10.80 \% \pm 2.48 \%$, $(\mathrm{P}=0.0001)$ but decrease in neutrophils to $3.30 \% \pm 1.23 \%$ as compared to day 9 (P $<0.003)$ although the number was still significantly higher $(\mathrm{P}<$ 0.034) than that of day 0 . The lymphocytes in BALF significant increased to $32.70 \% \pm 3.07 \%$, $(\mathrm{P}<0.0001)$ on day 14.

\subsubsection{Histopathological Changes in Airways}

The histopathological changes in the proximal and distal airways were determined to assess the initiation of airway hypersensitivity. In the proximal airways of sensitized animals, an increase in thickness of airway smooth muscle and multiple areas of epithelial denudation was observed on day 14 when compared to control (Figures 2(a) and (b). These changes were not observed on day 9. The distal airways revealed grade 1 , peribronchiolar chronic lymphocytic inflammation when compared to control on day 9 (Figures 3(a) and (b)). On day 14, pathological changes were of grade 2 which corresponded to infiltration of lymphocytes and eosinophils in the lung (Figure 3(c)). Further, the onset ofstructural remodelingofproximal and distal airwayswas observed in experimental group on day 14 in which ASM hypertrophy was seen in proximal airways (Figure 4(a)) while distal airways showed a mild increase in thickness of the subepithelial lamina reticularis (Figures 4(b)-(d)) as compared to control group.

\section{PKC Activity and Expression of Its Isoenzymesin Airway Smooth Muscles (ASM) and Lymphocytes}

To test our hypothesis that PKC could be a critical player during the initiation of airway hypersensitivity after sensitization, we examined the total PKC activity in ASM (Figures 5(a) and (b)) and lymphocytes (Figures 5(c) and (d)) isolated from control and ovasensitized group on days 0,9 and 14 . On day 0 , there was no significant change in the PKC activity in ASM and lymphocyte as compared to control group. However, on day 9, PKC activity, measured by two different methods, increased
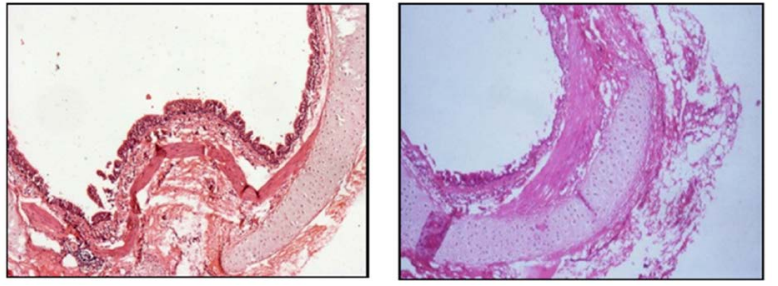

Figure 2. Pathological changes in proximal airways on day 14. H\&E stain $\times 40$. (a) Control group; showing normal histopathology and(b) Experimental group on day 14 showed epithelial denudation and airway smooth muscle hypertrophy.
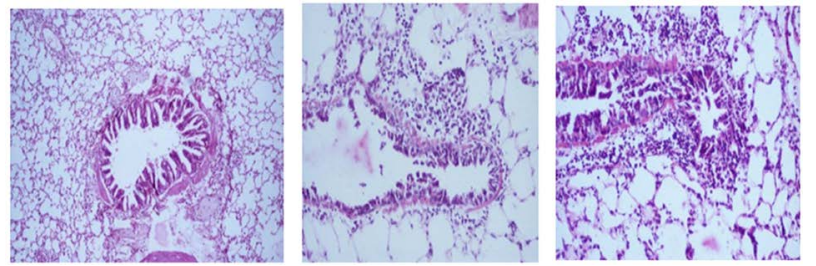

Figure 3. Distal airway inflammation, graded for peribronchiolar inflammation and percentage of eosinophilia $H \& E$ stain $\times 100$. (a) Control group, normal bronchiole and lung parenchyma. (b) Grade 1 peribronchiolar inflammation on day 9 and (c) Grade 2 peribronchiolar inflammation on day 14, comprising of eosinophils and lymphocytes. 


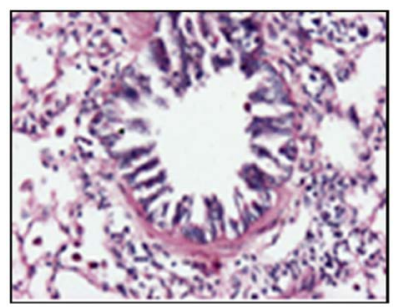

(a)

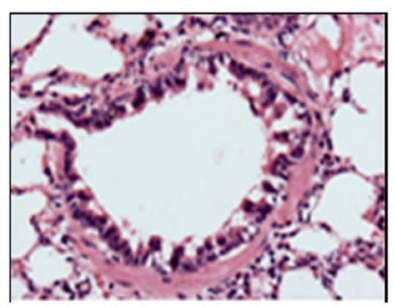

(c)

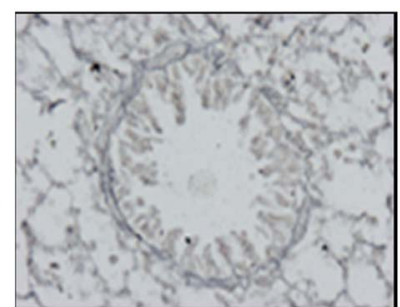

(b)

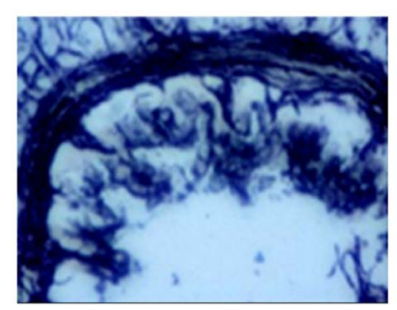

(d)
Figure 4. Structural changes in the distal airway. (a) Control group, H\&E stain $\times 200$. (b) Control group Gomori silver methenamine stain $($ GMS) $\times 200$. (c) On day 14 , mild increase in thickness of the subepithelial lamina reticularis, H\&E stain $\times 200$. (d) Laying down of reticulinfibres on day 14 , in subepithelial region highlighted by GMS stain $\times 400$. significantly in ASM ( $\mathrm{P}=0.0023$ and 0.0025 by radioligand and histone III phosphorylation methods, respectively) and lymphocytes ( $\mathrm{P}=0.0120$ and 0.0001 respectively). On day 14, the PKC activity further increased significantly in ASM ( $P=0.0004$ and 0.0011 respectively) as well as lymphocytes ( $\mathrm{P}=0.008$ and 0.0027 respectively). The increase in PKC activity on day 9 and further was $>45 \%$, suggesting physiological activation of the enzyme at the onset of the airway hypersensitivity.

Since increase in the activity as well as expression of PKC coincide with the days of Ova-induced airway hypersensitivity, these results suggest that PKC could be a key mediator of initiation of airway hypersensitivity in guinea pigs.

\section{Metabolism of Phosphoinositides in Airway Smooth Muscles and Lymphocytes}

Since PKC activity is regulated by the metabolic pool of phosphoinositides and their turnover, we next examined the changes in the total phosphoinositides in ASM and lymphocytes during the initiation of airway hypersensitivity. The phosphoinositides extracted and estimated

PKC activity in ASM

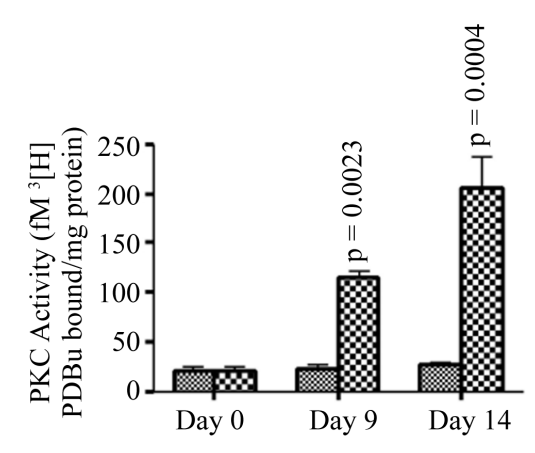

(a)

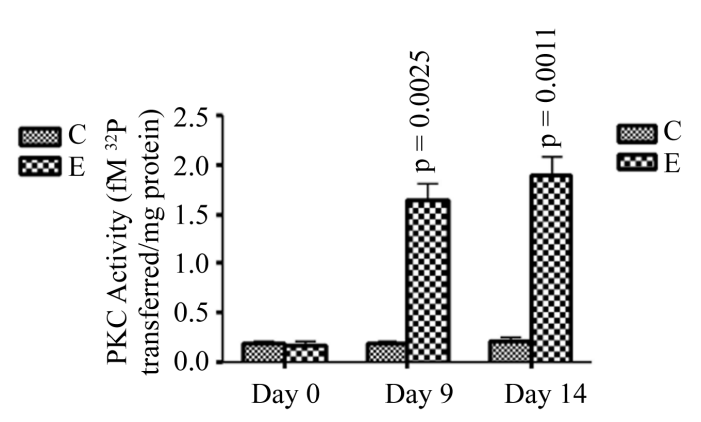

(b)

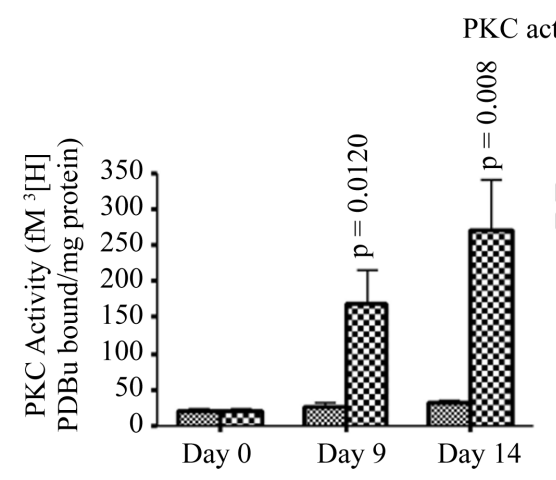

(c)

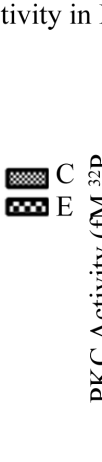

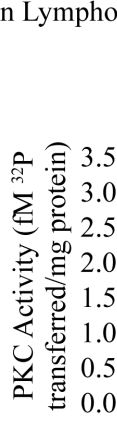

Figure 5. Assessment of PKC activity in Airway smooth muscle (ASM) and blood derived-lymphocytes. The PKC activity was measured by radio-ligand binding assay (a and c), expressed as mean \pm SEM femtomoles of $\left[{ }^{3} \mathrm{H}\right]$ DBu bound/mg protein in ASM or per $10^{6}$ lymphocytes and Histone phosphorylation $(b, d)$, expressed as mean \pm SEM femtomoles of ${ }^{32} \mathrm{P}$ transferred to IIIs histone per mg proteins in ASM or per $10^{6}$ lymphocytes. The activity is shown in control and experimental groups on day 0 , day 9 and day 14 representing baseline, the onset and full sensitization respectively ( $n=5$ in each group). 
were phosphatidyl inositol (PI), phosphatidyl inositol 4-monophosphate (PIP) and phosphatidyl inositol 4,5bisphosphate $\left(\mathrm{PIP}_{2}\right)$. In experimental group on day 0 , there was no change inPI, PIP and PIP $_{2}$ levels in ASM and lymphocytes as compared to control group (Table 1). On day 9, the level of PI increased significantly in ASM $(\mathrm{P}=0.0181)$ and lymphocytes $(\mathrm{P}=0.0087)$ as compared to control group. Similarly, the levels of PIP increased significantly in ASM $(\mathrm{P}=0.0285)$ and lymphocytes $(\mathrm{P}=$ 0.0076) as compared to control group. The levels of PIP $_{2}$ also increased significantly in ASM and lymphocytes (P $=0.0258$ and 0.0020 ) as compared to control group on day 9. On day 14, the levels of these phosphoinositide intermediates increased further in both ASM and lymphocytes as summarized in Table 1 . These results suggest that increased activity of PKC isoenzymes during initiation of airway hypersensitivity could be associated with increased levels of phosphoinositides in ova-sensitized and challenged animal.

\section{Discussion}

Asthma is a multifactorial airway inflammatory disease, characterized by airway inflammation, structural changes in the airway wall associated with progressive decline in lung function, and airway hyperresponsiveness (AHR) [5]. Most of the studies on bronchial asthma on the mechanism of stimulus-induced changes have been conducted after the manifestation of the disease, which do not represent its etiopathogenesis. We, therefore, investigated the biochemical changes in airway hyper reactive guinea pig model of asthma and have presented evidence that PKC isoenzymes could be key mediators in the initiation of airway hypersensitivity during the onset of asthma. Previously, several investigators have suggested that PKC plays an active role in the progression and ex- acerbation of asthma [16,17]. We have also demonstrated acerbation of asthma [16,17]. We have also demonstrated that PKC antagonist sphingosine reduced the T lymphocytes activity isolated from asthmatic patients [16]. Further, PKC inhibitor, Ro31-8220, has been shown to inhibit the expression of Th2 cytokines from asthmatic $\mathrm{T}$ lymphocytes [17], abolish airway smooth muscles constriction [18] and inhibit the proliferation and structural changes in airway smooth cells of asthmatic rats [19]. In another study, Lew et al. [20] showed that calphostin-C, a PKC inhibitor, prevented proliferation of bovine tracheal smooth muscle cells following activation of mannose receptors by $\beta$-hexosaminidase and also abolished $\mathrm{Ca}^{2+}$-dependent and -independent PKC activity. These evidences clearly demonstrate the role of PKC in asthma, but its role during the onset of the disease is not clearly understood. We therefore investigated the biochemical and molecular changes in airway hyper reactive guinea pig model of asthma and have presented evidence that PKC isoenzymes could be key mediators in the initiation of airway hypersensitivity during the onset of asthma. Immunoglobulin E (IgE) plays a central role in the pathogenesis of allergic diseases, including asthma [33, 34]. Allergic sensitization results from the formation of antigen-specific IgE in response to common inhalant allergens [35,36]. In our present study, on day 9 after sensitization the animals in the experimental group showed a significant positive response in i.d. which indicate that allergen-specific IgE were synthesized in enough amounts which could respond to the antigen as early as day 9. When these animals inhaled ovalbumin, they showed a significant airway hypersensitivity on day 9 , suggesting that day 9 was the accurate time point for the onset of the disease. The changes were further confirmed by histopathology of the lungs, e.g. there was a

Table 1. Phosphoinositides $\Psi$ in airway smooth muscles (ASM) and lymphocytes in control and experimental groups on various days after sensitization with ovalbumin.

\begin{tabular}{cccccc}
\hline \multirow{2}{*}{ Day } & Phosphoinositide & \multicolumn{3}{c}{ ASM } & \multicolumn{2}{c}{ Lymphocytes } \\
\cline { 3 - 6 } & & Control & Experimental & Control & Experimental \\
\hline \multirow{3}{*}{0} & PI & $0.328 \pm 0.028$ & $0.310 \pm 0.019$ & $0.336 \pm 0.047$ & $0.293 \pm 0.002$ \\
& PIP & $0.208 \pm 0.007$ & $0.237 \pm 0.018$ & $0.229 \pm 0.008$ & $0.304 \pm 0.043$ \\
& PIP2 & $0.367 \pm 0.022$ & $0.305 \pm 0.056$ & $0.354 \pm 0.020$ & $0.336 \pm 0.054$ \\
9 & PI & $0.339 \pm 0.047$ & $0.624 \pm 0.036^{*}$ & $0.272 \pm 0.047$ & $0.664 \pm 0.036^{* *}$ \\
& PIP & $0.240 \pm 0.045$ & $0.415 \pm 0.008^{*}$ & $0.253 \pm 0.018$ & $0.478 \pm 0.043^{* *}$ \\
& PIP2 & $0.312 \pm 0.009$ & $0.516 \pm 0.057^{*}$ & $0.345 \pm 0.029$ & $0.651 \pm 0.005^{* *}$ \\
& PI & $0.270 \pm 0.016$ & $0.704 \pm 0.074^{*}$ & $0.358 \pm 0.041$ & $0.862 \pm 0.014^{* *}$ \\
& PIP & $0.264 \pm 0.039$ & $0.449 \pm 0.042^{*}$ & $0.282 \pm 0.032$ & $0.450 \pm 0.030^{*}$ \\
& PIP2 & $0.315 \pm 0.035$ & $0.722 \pm 0.045^{* *}$ & $0.311 \pm 0.033$ & $0.794 \pm 0.065^{*}$ \\
\hline
\end{tabular}

$\boldsymbol{\Psi}$ Expressed as $\mu \mathrm{g} \mathrm{P}_{\mathrm{i}} / \mathrm{mg}$ proteins (Mean $\pm \mathrm{SEM}$ ), $\mathrm{n}=5$ in each group; PI: Phosphatidyl inositol, PIP: Phosphatidyl inositol 4-monophosphate, PIP $\mathbf{P}_{2}$ Phosphatidyl inositol 4, 5 bisphosphate; ${ }^{*} \mathrm{P}<0.05,{ }^{* *} \mathrm{P}<0.01$. 
significant increase in the total BALF cell counts on day 9, the first day of initiation of hypersensitivity in experimental group, which further increased (3.5 fold) on day 14, similar to the findings of Sakai et al. [37].

PKC is one of the key enzymes that mediate inflammatory signals [38]. It represents a structurally homologous group of 12 isoforms which are divided into three sub-groups that differ in their cofactor requirements. These are conventional(c) PKC isoforms $\left(\alpha, \beta_{\mathrm{I}}, \beta_{\text {II }}\right.$ and $\gamma$ ) that require $\mathrm{Ca}^{2+}$ and diacylglycerol (DAG) for activation, novel (n) PKC isoforms $\left(\delta, \varepsilon, \zeta, \theta\right.$ and $\mu$ ) that are $\mathrm{Ca}^{2+}$ independent but require DAG and the atypical (a) PKC isoforms, namely $\zeta, \imath$ and $\lambda$ (the mouse homologue of human $\mathrm{PKCl}$ ), that do not require $\mathrm{Ca}^{2+}$ or DAG $[14,39]$.

One of the major signaling pathways that involves PKC is the hydrolysis of membrane $\mathrm{PIP}_{2}$ by phospholipase C (PLC) that generates $\mathrm{IP}_{3}$ and DAG $[14,40]$, which then activate PKC [40]. Activated PKC then phosphorylates downstream signaling protein kinases leading to activation of transcription factors such as NF-kB which in turn transcribe many inflammatory genes resulting in inflammatory response and pathophysiological changes in affected cells. In views of this, the role of PKC isoenzymes is crucial in the activation of inflammatory signals (Figure 6). PKC activity is influenced by the metabolic pool of phosphoinositides and their turnover [40]. The increase in phosphoinositides pool may be due to their increased biosynthesis or decreased breakdown by the phosphomonoesterases. The phosphoinositides are metabolized by two different pathways. In one pathway activation of phosphoinositide-specific phospholipase C (PLC) leads to the generation of diacylglycerol (DAG) and inositol triphosphate $\left(\mathrm{IP}_{3}\right)$ which act as second messengers and activate PKC [42]. In the other pathway, phosphatidyl inositol -3 kinase (PI-3K) phosphorylates and converts the inositol of various phosphoinositides into respective phosphoinositide 3 phosphate species [41, 42], the levels of which are regulated by specific phosphatases. We observed that the total contents of the phosphoinositides (PI, PIP, and $\mathrm{PIP}_{2}$ ) were significantly increased on day 9 after Ova-sensitization, which coincided with significantly increased antigen-specific immune response and airway hypersensitivity. The increase in the levels of PIs was associated with corresponding increase in the total PKC enzyme activity in airway smooth muscles and blood lymphocytes. These changes were further confirmed by the histopathological changes of the distal airways which showed lymphocytic infiltration (pathological grade 1), suggesting that increased activity and expression of PKC could lead to the activation of $\mathrm{T}$ cells and play a pivotal role in the pathophysiology, specifically during initiation of asthma. The increased PKC $\alpha$ activity on day 9 suggests the activation of conventional PKCs which require calcium and DAG

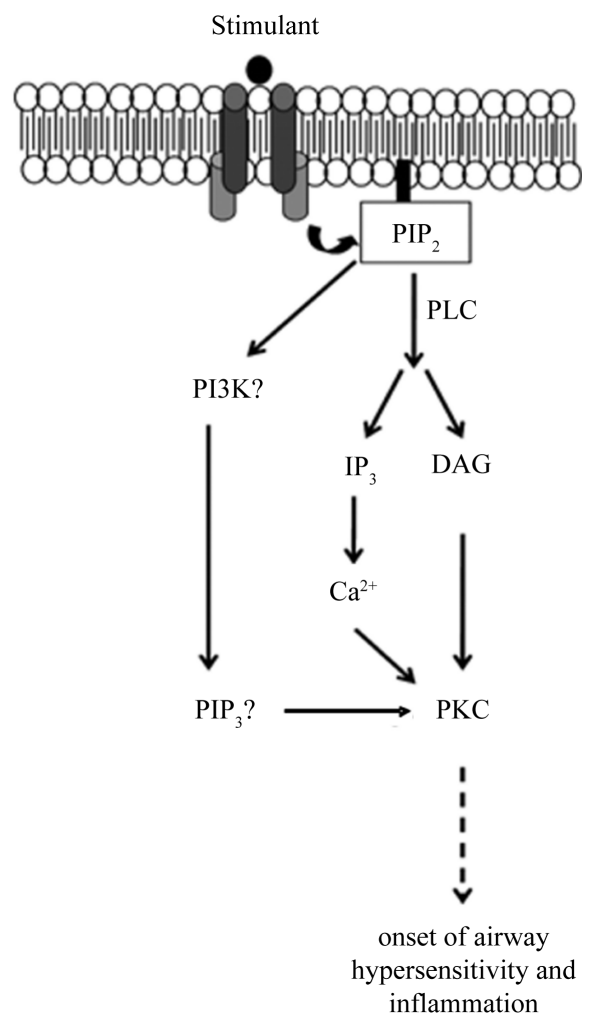

Figure 6. Schematic presentation of molecular mechanism involved in the onset of airway hypersensitivity $\mathrm{PKC}=$ protein kinase C, DAG = sn 1, 2 diacylglycerol, PIP2 = phosphoinositol 4, 5 bisphosphate, PLC = phospholipase C, IP3 = Inositol 1, 4, 5 triphospahte, PI3K = Phosphatidyl inositol triphosphate kinase, PIP3 = Phosphatidyl inositol triphosphate.

for their activation [39]. It is known that increase in intracellular calcium is transient and tightly regulated. After being released from intracellular pools, the level of calcium returns to normal rather quickly [40], suggesting that initiation of airway hypersensitivity and inflammation on day 9 could involve activation of PKC $\alpha$, which probably trigger the onset of the disease. However, for long term sustenance of the pathology as in chronic asthma, calcium-independent mechanism will be required [40]. Ono et al. have suggested that novel PKCs do not require calcium for their activation and have been implicated in the progression of asthma [43]. The significantly increased expression of PKC $\varepsilon$ by day 14 , when the immune response was fully established, as evident by maximum i.d.positivity and airway hypersensitivity, indicates that sustained activation of novel PKCs in ASM and lymphocytes could be responsible for the progression of the disease. Since in our study there was no change in the expression of PKC- $\tau$ on day 9, it could be stipulated that atypical PKCs, whose activation is independent of calcium and/or DAG, do not play any significant role in the onset of the airway inflammation [39]. These findings 
suggest that the onset of airway inflammation requires $\mathrm{Ca}^{2+}$ and DAG initially and activation of DAG-dependent mechanism in the later stage of asthma pathogenesis.

In summary, the results of this study suggest that PKC signal transduction pathway participates in onset of airway hypersensitivity and inflammation by regulating activation of lymphocytes and ASM. Therefore, the use of PKC antagonist may be a promising approach towards prevention of asthma.

\section{Conclusion}

The study established the day $9^{\text {th }}$ to be the day of onset of airway inflammation and hypersensitivity in the guinea model of ovalbumin and day $14^{\text {th }}$ to be the day when the hypersensitivity is fully developed. During the onset of the disease, the activation of PKC, particularly PKC $\alpha$ and $\mathrm{PKC} \varepsilon$, mediated signal transduction pathway plays a critical role in lymphocyte infiltration and onset of airway hypersensitivity, airway remodeling and asthma pathophysiology. This study is the first one which shows a direct evidence of the role of PKC mediated pathway in the onset of airway hypersensitivity and the mechanism of the etiopathogenesis of the disease in ovalbumin sensitized guinea pig model.

\section{Acknowledgements}

Financial support to RKM in the form of UGC-PhD Research Fellowship by University of Delhi is thankfully acknowledged. The authors are also thankful to Mr. SanjayGoel for providing technical support during the study.

\section{REFERENCES}

[1] C. R. Stephen, "Asthma in the United States: Burden and Current Theories,” Environmental Air Toxics, Vol. 110, No. 4, 2002, pp. 557-560.

[2] M. Masoli, D. Fabian, S. Holt and R. Beasley, "The Global Burden of Asthma: Executive Summary of the GINA Dissemination Committee Report,” Allergy, Vol. 59, No. 5, 2004, pp. 469-478.

http://dx.doi.org/10.1111/j.1398-9995.2004.00526.x

[3] H. Paramesh, "Epidemiology of Asthma in India," The Indian Journal of Pediatrics, Vol. 69, No. 4, 2002, pp. 309-312. http://dx.doi.org/10.1007/BF02723216

[4] S. K. Jindal, "Bronchial Asthma: The Indian Scene," Current Opinion in Pulmonary Medicine, Vol. 13, No. 1, 2007, pp. 8-12.

http://dx.doi.org/10.1097/MCP.0b013e32800ffd09

[5] J. Bousquet, P. K. Jeffery, W. W. Busse, M. Johnson and A. M. Vignola, "Asthma from Bronchoconstriction to Airways Inflammation and Remodeling,” American Journal of Respiratory and Critical Care Medicine, Vol. 161, No. 5, 2000, pp. 1720-1745. http://dx.doi.org/10.1164/ajrccm.161.5.9903102

[6] D. E. Davies, J. Wicks, R. M. Powell, S. M. Puddicombe and S. T. Holgate, "Airway Remodeling in Asthma: New Insights,” The Journal of Allergy and Clinical Immunology, Vol. 111, No. 2, 2003, pp. 215-225. http://dx.doi.org/10.1067/mai.2003.128

[7] A. J. James, "Relationship between Airway Wall Thickness and Airway Hyperresponsiveness,” In: A. G. Stewart, Ed., Airway Wall Remodeling in Asthma, CRC Press, Boca Raton ,1997, pp. 1-27.

[8] A. L. James, P. D. Pare and J. C. Hogg, "The Mechanics of Airway Narrowing in Asthma," American Review of Respiratory Disease, Vol. 139, No. 1, 1989, pp. 242-246. http://dx.doi.org/10.1164/ajrccm/139.1.242

[9] C. P. Brewster, P. H. Howarth, R. Djukanovic, J. Wilson, S. T. Holgate, et al., "Myofibroblasts and Subepithelial Fibrosis in Bronchial Asthma," American Journal of Respiratory Cell and Molecular Biology, Vol. 3, No. 5, 1990, pp. 507-511. http://dx.doi.org/10.1165/ajrcmb/3.5.507

[10] T. Aikawa, S. Shimura, H. Sasaki, M. Ebina and T. Takashima, "Marked Goblet Cell Hyperplasia with Mucus Accumulation in the Airways of Patients Who Died of Severe Acute Asthma Attack,” Chest, Vol. 101, No. 4, 1992, pp. 916-921. http://dx.doi.org/10.1378/chest.101.4.916

[11] J. L. Devalia, C. Rusznak, J. Wang, O. A. Khair, M. M. Abdelaziz, et al., "Air Pollutants and Respiratory Hypersensitivity,” Toxicology Letters, Vol. 86, No. 2-3, 1996, pp. 169-176. http://dx.doi.org/10.1016/0378-4274(96)03687-9

[12] M. Lipsett, S. Hurley and B. Ostro, “Air Pollution and Emergency Room Visits for Asthma in Santa Clara County, California,” Environmental Health Perspectives, Vol. 105, No. 2, 1997, pp. 216-222. http://dx.doi.org/10.1289/ehp.97105216

[13] K. B. Charlotte and B. Raymond, "Penn. m3 Muscarinic Acetylcholine Receptor Regulation in the Airway," American Journal of Respiratory Cell and Molecular Biology, Vol. 26, No. 3, 2002, pp. 269-272. http://dx.doi.org/10.1165/ajrcmb.26.3.f232

[14] Y. Nishizuka, "Prespectives on Protein Kinase C," Science, Vol. 233, No. 4761, 1986, pp. 305-312. http://dx.doi.org/10.1126/science.3014651

[15] R. Rasmussen, Y. Takuwa and S. Park, "Protein Kinase C in the Regulation of Smooth Muscle Contraction," The FASEB Journal, Vol. 1, No. 3, 1987, pp. 177-185.

[16] S. K. Bansal, A. Jha, A. S. Jaiswal and S. K. Chhabra, "Increased Levels of Protein Kinase C in Lymphocytes in Asthma: Possible Mechanism of Regulation,” European Respiratory Journal, Vol. 10, No. 2, 1997, pp. 308-313. http://dx.doi.org/10.1183/09031936.97.10020308

[17] W. Xiong. Y. Xu, Z. Zhang, X. Wang, B. Mo and J. Fu, "An Experimental Study on the Regulation of Expression of Th2 Cytolines from T Lymphocytes by Protein Kinase C in Asthma," Journal of Tongji Medical University, Vol. 21, No. 4, 2001, pp. 292-296. http://dx.doi.org/10.1007/BF02886560

[18] D. Cheng, Y. Xu, X. Liu, L. Zhao, S. Xiong, et al., “The Effects of Protein Kinase C (PKC) on the Tension of Normal and Passively Sensitized Human Airway Smooth Muscle and the Activity of Voltage-Dependent Delayed 
Rectifier Potassium Channel (Kv),” Journal of Huazhong University of Science and Technology, Vol. 27, No. 2, 2007, pp. 153-156.

http://dx.doi.org/10.1007/s11596-007-0211-1

[19] L. F. Qiao, Y. J. Xu, X. S. Liu, J. G. Xie, J. Wang, et al., "Role of Protein Kinase C Alpha and Cyclin D1 in the Proliferation of Airway Smooth Muscle in Asthmatic rates,” Chinese Medical Journal, Vol. 121, No. 20, 2008, pp. 2070-2076.

[20] D. B. Lew, E. R. Brown, B. K. Dempsey, H. M. Wright and K. U. Malik, "Contribution of PKC to b-Hexosaminidase-Induced Airway Smooth Muscle Proliferation,” American Journal of Physiology, Vol. 272, No. 4, 1997, pp. 639-643.

[21] R. E. Santing, Y. Pasman, C. G. Olymulder, A. F. Roffel, H. Meurs, et al., "Contribution of Cholinergic Reflx Mechanism of Allergen Induced Bronchial Hyperreactivity in Permanently Instrumented, Unrestrained Guinea Pigs,” British Journal of Pharmacology, Vol. 114, No. 2, 1995, pp. 414-418. http://dx.doi.org/10.1111/j.1476-5381.1995.tb13242.x

[22] K. P. Agarwal, "Specific Airway Conductance in Guinea pigs: Normal Values and Histamine Induced Fall," Respiration Physiology, Vol. 43, No. 1, 1981, pp. 23-30. http://dx.doi.org/10.1016/0034-5687(81)90085-2

[23] S. K. Bansal and J. L. Kaw, "Lactate Dehydrogenase Isoenzymes in Alveolar Macrophages and Serum during the Development of Pulmonary Silicosis," Toxicology Letters, Vol. 7, No. 7, 1981, pp. 279-283

[24] S. K. Bansal, "Carbohydrate Metabolism in the Rat Peritoneal Macrophages,” Journal of Biosciences, Vol. 12, No. 4, 1987, pp. 415-420. http://dx.doi.org/10.1007/BF02898591

[25] S. Underwood, M. Foster, D. Raeburn, S. Bottoms and J.-A. Karlsson, “Time-Course of Antigen-Induced Airway Inflammation in the Guinea Pigs and Its Relationship to Airway Hyperresponsivness,” European Respiratory Journal, Vol. 8, No. 12, 1995, pp. 2104-2113. http://dx.doi.org/10.1183/109031936.95.08122104

[26] A. Al-Shami, R. Spolski, J. Kelly, A. Keane-Myers and W. J. Leonard, "A Role for TSLP in the Development of Inflammation in an Asthma Model," The Journal of EXperimental Medicine, Vol. 202, No. 6, 2005, pp. 829-839. http://dx.doi.org/10.1084/jem.20050199

[27] A. Boyum, "Isolation of Lymphocytes, Granulocytes and Macrophages," Scandinavian Journal of Immunology, Vol. 5, No. s5, 1976, pp. 9-15. http://dx.doi.org/10.1111/j.1365-3083.1976.tb03851.x

[28] O. H. Lowry, N. J. Rosebrough, A. L. Farr and R. J. Randal, "Protein Measurement with the Folinphenol Reagent," The Journal of Biological Chemistry, Vol. 193, No. 1, 1951, pp. 265-275.

[29] S. K. Bansal, R. Kathyat, A. S. Jaiswal, K. K. Taneja, P. Malhotra, et al., "Effect of Feeding Protein Deficient Diet on Phospholipid Turnover and Protein Kinase C Mediated Protein Phosphorylation in Rat Brain,” Indian Journal of Experimental Biology, Vol. 38, No. 4, 2000, pp. 323-331.

[30] M. M. Billah and E. G. Lapetina, "Rapid Decrease of Phosphoinositol 4, 5 Bisphosphate in Thrombin Stimu- lated Platelets,” The Journal of Biochemistry, Vol. 257, No. 12, 1982, pp. 12705-12708.

[31] U. K. Misra, "Thin Layer Chromatographic Estimation of Rat Plasma and Tissue Lipids,” BiochemBiolSper, Vol. 7, No. 5, 1986, pp. 57-59.

[32] A. S. Jaiswal, U. K. Misra and S. K. Bansal, "Differential Activity of PKC in Alveolar and Peritoneal Macrophages,” Indian Journal of Biochemistry \& Biophysics, Vol. 33, No. 2, 1996, pp. 116-121.

[33] E. O. Charles, "Immunoglobulin E: Role in Asthma and Allergic Disease: Lessons from the Clinic,” Pharmacology \& Therapeutics, Vol. 113, No. 1, 2007, pp. 121-133. http://dx.doi.org/10.1016/j.pharmthera.2006.07.003

[34] G. D. Marshall, "Internal and External Environmental Influences in Allergic Diseases," Journal of the American Osteopathic Association, Vol. 104, No. 5, 2004, pp. 1-5.

[35] C. H. Hsu, K. Y. Chua, M. H. Tao, S. K. Huang and K. H. Hsieh, "Inhibition of Specific IgE Response in vivo by Allergen-Gene Transfer,” International Immunology, Vol. 8, No. 9, 1996, pp. 1405-1411. http://dx.doi.org/10.1093/intimm/8.9.1405

[36] P. Eigenmann, L. Tropia and C. Hauser, "1L-10 Induces Antigen-Specific T-Cell Anergy but no Regulatory T Cells in Children with Egg Allergy," Journal of Allergy and Clinical Immunology, Vol. 111, No. 1, 2009, pp. 106-107.

[37] K. Sakai, A. Yokoyama, N. Kohno and K. Hiwada, "Effect of Different Sensitizing Doses of Antigen in a Murine Model of Atopic Asthma," Clinical \& Experimental Immunology, Vol. 118, No. 1, 1999, pp. 9-15. http://dx.doi.org/10.1046/j.1365-2249.1999.01036.x

[38] S. E. Wilkinson and J. S. Nixon, "T-Cell Signal Transduction and the Role of Protein Kinase C," Cellular and Molecular Life Sciences CMLS, Vol. 54, No. 10, 1998, pp. 1122-1144. http://dx.doi.org/10.1007/s000180050241

[39] B. L. Webb, S. J. Hirst and M. A. Giembycz, "Protein Kinase C Isoenzymes: A Review of Their Structure, Regulation and Role in Regulating Airways Smooth Muscle Tone and Mitogenesis,” British Journal of Pharmacology, Vol. 130, No. 7, 2000, pp. 1433-1452. http://dx.doi.org/10.1038/sj.bjp.0703452

[40] M. J. Berridge, "Inositol Triphosphate and Calcium Signaling,” Nature, Vol. 361, No. 14, 1993, pp. 315-325. http://dx.doi.org/10.1038/361315a0

[41] M. J. Fry, "Structure, Regulation and Function of Phosphoinositide 3-Kinases," Biochimica et Biophysica Acta, Vol. 1226, No. 3, 1994, pp. 237-268. http://dx.doi.org/10.1016/0925-4439(94)90036-1

[42] K. Ito, G. Caramori and I. M. Adcock, "Therapeutic Potential of Phosphatidylinositol 3-Kinase Inhibitors in Inflammatory Respiratory Disease," The Journal of Pharmacology and Experimenal Theraupeutics, Vol. 321, No. 1, 2007, pp. 1-8.

[43] Y. Ono, T. Fujii, K. Igarashi, T. Kuno, C. Tanaka, U. Kikkawa and Y. Nishizuka, "Phorbol Ester Binding to Protein Kinases Requires a Cysteine-Rich Zinc-Finger-Like Sequence," Proceedings of the National Academy of the Sciences of the United States of America, Vol. 86, No. 13, 1989, pp. 4868-4871. http://dx.doi.org/10.1073/pnas.86.13.4868 